\title{
En bloc resection of carcinoid tumor by a hybrid endoscopic submucosal dissection technique
}

Rectal carcinoids are rare tumors, most of which are diagnosed incidentally during routine colonoscopy. Unfortunately, endoscopists tend to attempt resection using traditional resection methods, such as snare, which often results in incomplete resection [1-2]. The endoscopic submucosal dissection (ESD) method has recently been proposed as a valuable endoscopic treatment for rectal carcinoids, because it provides a higher en bloc resection rate than conventional endoscopic mucosal resection (EMR), enabling accurate pathologic diagnosis and potentially curative treatment [3-5].

A 66-year-old woman was evaluated by upper and lower gastrointestinal endoscopies in 2015 for epigastralgia without other accompanying symptoms. During colonoscopy, an 8-mm rectal polyp with a preserved mucosal pattern was found about $3 \mathrm{~cm}$ proximally to the dentate line ( Fig. 1 a). Pathological assessment reported a well-differentiated carcinoid tumor (G1), based on a mitosis count of 1 per high-power field and Ki67 staining of less than $2 \%$. Abdominal and pelvic computed tomography (CT) scans and the level of 5-hydroxyindoleacetic acid were unremarkable. No endosonography was performed as part of the staging because locoregional staging in carcinoids less than $1 \mathrm{~cm}$ has low sensitivity and resection serves as both a diagnostic and therapeutic procedure.

The lesion was resected using the ESD technique ( $\vee$ Video 1$)$. Resection margins were marked using a $2.5-\mathrm{mm}$

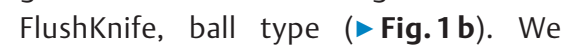
performed careful full-thickness wall sectioning, preserving the previously marked margins. After completing sectioning of the perimeter of the margins, we proceeded to complete the resection with a polypectomy snare ( $\mathbf{F i g . 1} \mathbf{c}, \mathbf{d}$ ). Histological analysis of the specimen showed a tumor $6 \mathrm{~mm}$ in diameter and 3-mm thick with mucosal involvement and part of the submucosa with tumor-
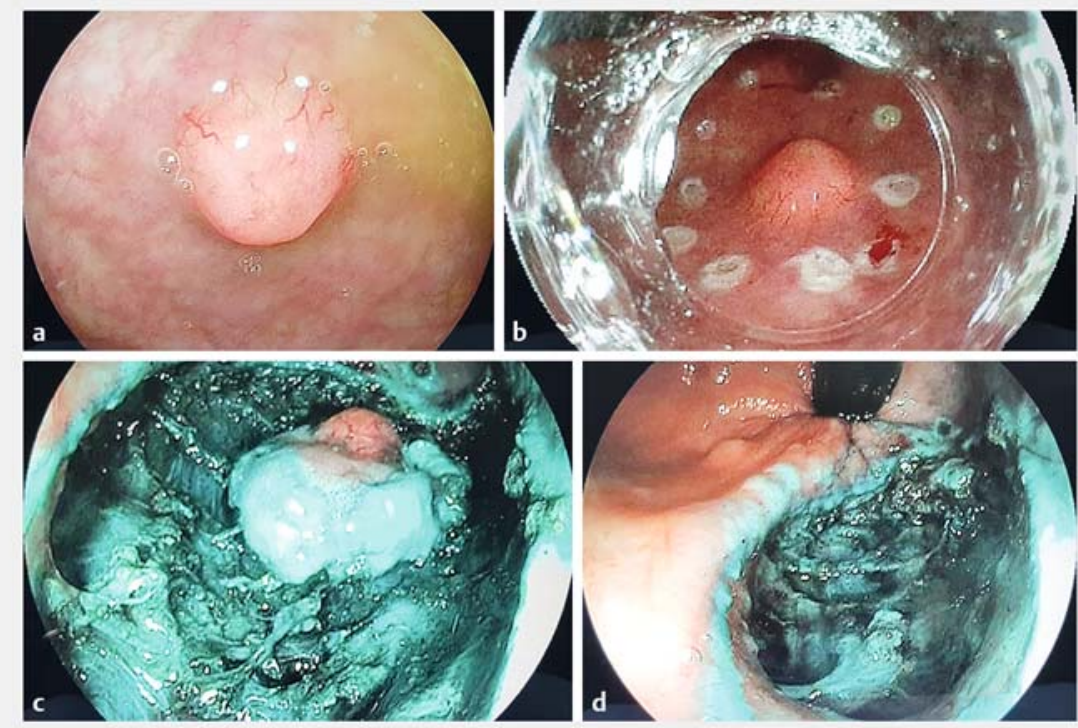

- Fig. 1 Endoscopic views showing: a a carcinoid tumor; b markings made around the margins of the lesion; $c$ tumor resection along with full-thickness resection of the rectal wall; d the defect following resection with perirectal fat visible in the depth of the lesion - the lesion was left open to heal spontaneously owing to its location.

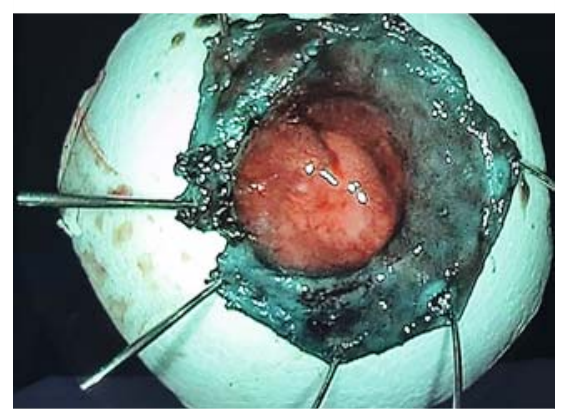

Fig. 2 Macroscopic appearance of the resected pathological specimen containing the tumor and peripheral tissue.

free lateral and vertical margins, confirming a surgical R0 resection ( $\mathbf{F i g} . \mathbf{2}$ ). The patient's postoperative course was uneventful and endoscopic follow-up at 3 months showed a scar with no macroscopic signs of relapse. The patient remains under follow-up at 12 months with no recurrence of her disease ( Fig.3).

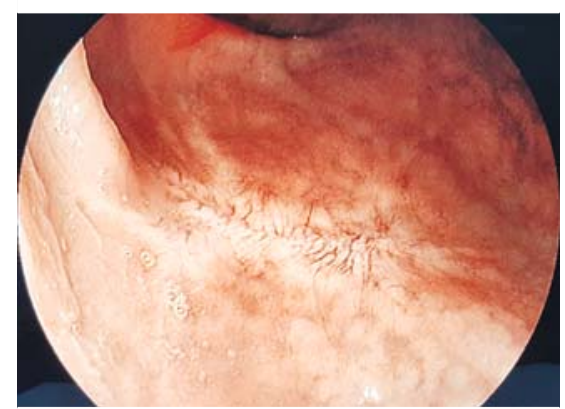

- Fig. 3 Follow-up endoscopy 3 months post-intervention showing a scar at the resection site.

In expert hands, full-thickness resection is an effective treatment for early lower rectal submucosal carcinoids, achieving curative treatment with a minimal incidence of abdominal complications.

Endoscopy_UCTN_Code_TTT_1AQ_2AD 


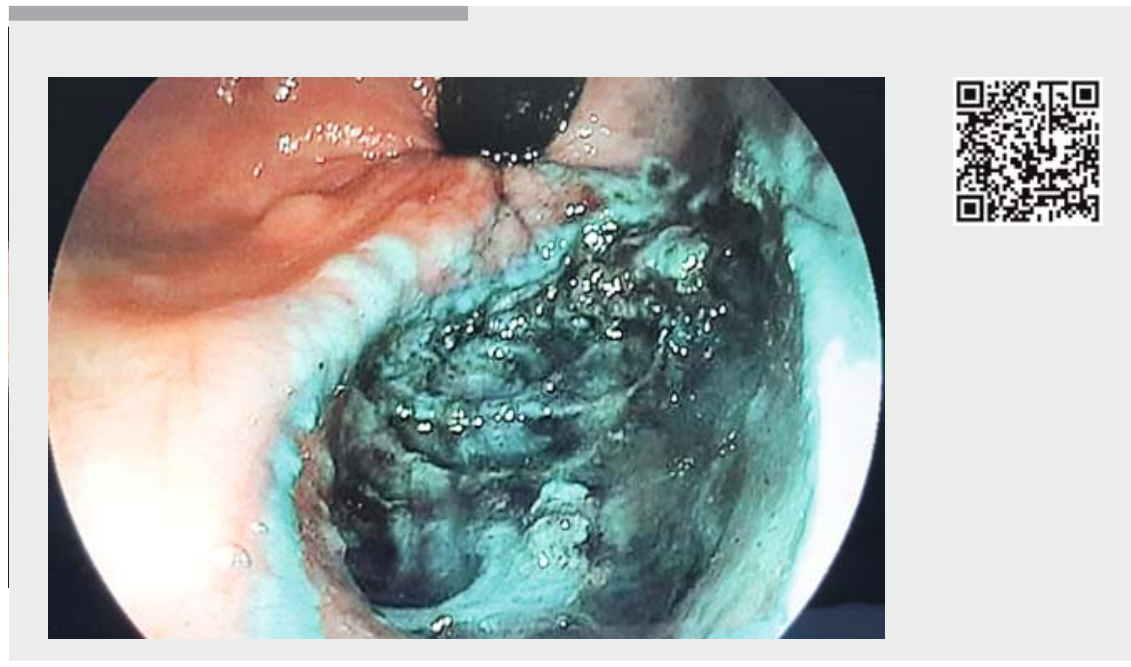

Video 1 A carcinoid tumor of $1 \mathrm{~cm}$ in diameter is identified in the lower rectum. Resection margins are marked and careful full-thickness wall sectioning is performed, preserving the previously marked margins. After sectioning of the perimeter of the margins has been completed, resection is completed with a polypectomy snare.

\section{Competing interests}

None

The authors

Sergio Rubel Cohen ${ }^{1}$, Fernando G. Fluxa², Pablo Fabre ${ }^{1}$, Fernando Uribe Reyes ${ }^{1}$, Mara Ferraris $^{2}$

1 Department of Endoscopy, Hospital Barros Luco Trudeau, Santiago de Chile, Chile

2 Department of Endoscopy, Clinica Las Condes, Las Condes, Metropolitan Region, Chile

\section{Corresponding author}

\section{Pablo Fabre, MD}

Hospital Barros Luco Trudeau - Endoscopy, Gran Avenida Jose Miguel Carrera 3204 Santiago de Chile 8900000 , Chile Fax: +2-2576-3000

fabrepablo@gmail.com

\section{References}

[1] Anthony L, Strosberg J, Klimstra D et al. The NANETS consensus guidelines for the diagnosis and management of gastrointestinal neuroendocrine tumors (NETs): well-differentiated NETs of the distal colon and rectum. Pancreas 2010; 39: $767-774$

[2] Kasuga A, Chino A, Uragami $N$ et al. Treatment strategy for rectal carcinoids: a clini- copathological analysis of 229 cases at a single cancer institution. J Gastroenterol Hepatol 2012; 27: 1801 - 1807

[3] Gleeson F, Levy M, Dozois E et al. Endoscopically identified well-differentiated rectal carcinoid tumors: impact of tumor size on the natural history and outcomes. Gastrointest Endosc 2014; 80: $144-151$

[4] Zhang J, Liu M, Li H et al. Comparison of endoscopic therapies for rectal carcinoid tumors: Endoscopic mucosal resection with circumferential incision versus endoscopic submucosal dissection. Clin Res Hepatol Gastroenterol 2018; 42: 24-23

[5] Li X, Gui Y, Han W et al. Application value of endoscopic submucosal dissection and endoscopic mucosal resection for treatment of rectal carcinoids. J Cancer Res Ther 2016 (Suppl. 12): 43-46

\section{Bibliography}

DOI https://doi.org/10.1055/a-0667-7573

Published online: 17.10 .2018

Endoscopy 2018; 50: E346-E347

(c) Georg Thieme Verlag KG

Stuttgart · New York

ISSN 0013-726X

\section{ENDOSCOPY E-VIDEOS \\ https://eref.thieme.de/e-videos}

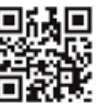

Endoscopy E-Videos is a free access online section, reporting on interesting cases and new

techniques in gastroenterological endoscopy. All papers include a high quality video and all contributions are freely accessible online.

This section has its own submission website at

https://mc.manuscriptcentral.com/e-videos 